\title{
XVI. On the application of the photographic camera to meteorological registration
}

\author{
Henry Collen Esq.
}

To cite this article: Henry Collen Esq. (1846) XVI. On the application of the photographic camera to meteorological registration , Philosophical Magazine Series 3, 28:185, 73-75, DOI: $10.1080 / 14786444608645364$

To link to this article: http://dx.doi.org/10.1080/14786444608645364

曲 Published online: 30 Apr 2009.

Submit your article to this journal $\lceil\pi$

Џ Article views: 2

Q View related articles 5 
'I'HE

LONDON, EDINBURGH AND DUBLIN

PHILOSOPHICAL MAGAZINE

\author{
A N I) \\ JOURNAL OF SCIENCE.
}

['THIRD SERIES.]

$F E B R U A R Y 1846$.

XVI. On the Application of the Photographic Camera to Meteorological Registration. By Henry Collen, Esq.*

[With a Plate.]

IN April 1844, Mr. Ronalds applied to me for the purpose 1 of obtaining some photographic representations of figures, forming " a sort of pictorial register of atmospheric electricity" upon glass plates coated with Canada balsam, which figures had been executed at the Kew Observatory by means of his electrograph, described in the Fourteenth Report of the British Association. The desired result was quickly obtained by the usual photogenic process, and also by the camera; the latter being found however, as was to be expected, the greatly superior mode. Several other impressions were afterwards made from figures on coated metallic plates, some of which were shown attached to Mr. Ronalds's report to the meeting at York. The sharpness and delicacy of the positive impressions thus obtained gave rise to some experiments, made by us conjointly, for the purpose of applying the photographic camera to the registration of Volta's electrometer, the thermometer, and the siphon barometer. The projection of shadows on photographic paper, which, by the way, had been already proposed and tried by several persons, was at once objected to by $\mathrm{Mr}$. Ronalds, whose knowledge of the delicacy required in observing and registering the karious instruments at the Observatory, made him fully aware of the necessity of obtaining as perfect definition as the best optical arrangement would produce; an excellent compound lens, made and kindly lent to us by Mr. Ross, was therefore used, and has been employed on each of the instruments, i. e. the electro-

* Communicated by the Author.

Phil. Mag. S. 3. Vol. 28. No. 185. Feb. 1846. 


\section{4}

Mr. H. Collen on the Application of Photography.

meter, the barometer, and the thermometer, and a series of experimental observations permanently registered at Kew.

The accompanying figure (Plate III. fig. 1) is part of a day's registration of the effect of atmospheric electricity on Volta's electrometer; the gradual decline of daylight is shown, and also the continuation of the registration, by artificial light; without the use of the latter, it is obvious that the application of photography to these purposes would be very incomplete, if not wholly useless; and it may perhaps, in some cases, be advisable to make its use constant.

The various intensities of light from a clouded sky frequently give rise (of course) to variations in depth of tint on the paper, which thus becomes an approximation to Sir John Herschel's actinograph ; and it may be here worth while to remark, that sometimes, when with such a sky these intensities of action on the paper are augmented, the electricity of serene weather manifests a tendency to increase also; this fact may be compared with the almost invariable tendency of the sun's light and heat, in a clear sky, to diminish the tension of those electrometers which receive their charges by absorption.

The calutype process is that which is used, being, of all those upon paper, the most sensitive, which quality is highly essential during the use of artificial light; it is very advantageously employed for these purposes, instead of the Daguerreotype, on account of its cheapness, and also on account of the facility with which representations can be obtained of any required length.

In the apparatus at present constructed, the paper is moved by a clock at the rate of one inch per hour, and is cut into pieces nine inches long; but for constant use they should be twelve inches long, so that by the introduction of two pieces during twenty-four hours, a continuous register of the effects would be preserved without further attention than the application of the artificial light (if not used constantly) at the decline of daylight; at present an Argand lamp is used, which, of course, requires some attention, but where available, a common gas-light woukl be greatly preferable; this however is not the case at the Kew Observatory, and for this renson only, the experiments have not been continued during the night.

The construction of the apparatus is very simple, although many tedious experiments have been made to produce the result; it consists essentially of the following arrangement:'The instrument to be registered is placed so as to be between the light and a lens of considerable aperture, with very short focus, and flat field of sufficient extent for the purpose; and 
Phit. Mag. s.5. Toldurim. Pl.II.

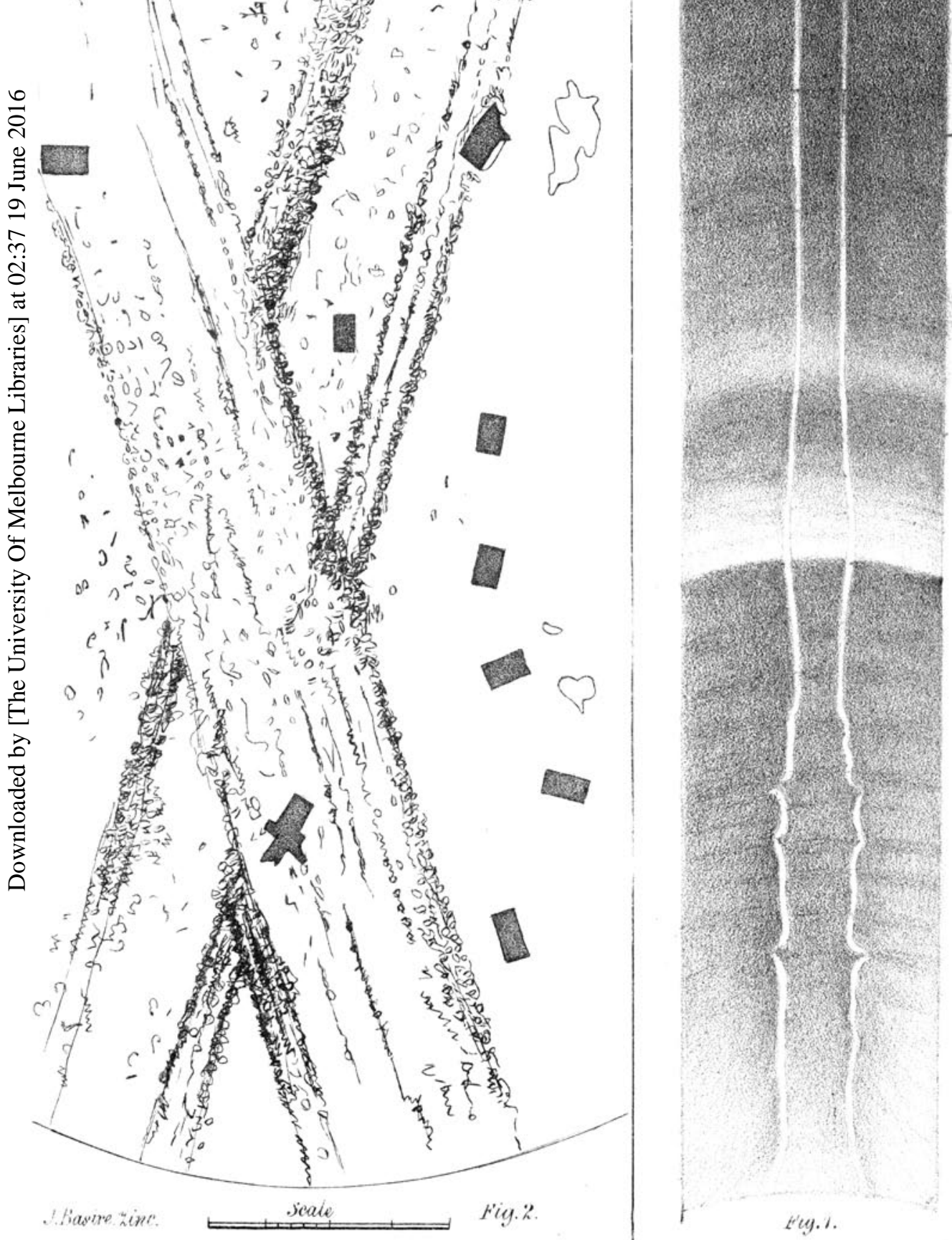


the paper is placed so as to be in the exact focus for obtaining an image of the same size as, or larger than, the object. When the electrometer is the instrument to be registered, the figures of the extreme ends only of the straws are allowed to fall upon the paper, an opake diaphragm pierced with a slit, the curve of which is part of a circle of which the length of the straws is the radius, being placed very near the paper.

In the registration of the thermometer or barometer, the difficulty arising from the refraction of light by the glass tube was proposed to be met in two ways, the first of which, the one adopted, consists in the use of a diaphragm with a straight slit, which can be opened from, or contracted towards, its exact centre by a very simple arrangement, and is placed in front of the mercury, i.e. on the side next to the light, so as to regulate the quantity admitted; this regulation has also the effect of preserving the necessary sharpness of figure, which too much light tends to injure.

'The second method proposed, which has not yet been tried, consists in the employment of a piece of glass tube, the bore of which is a trifle larger than the outside of the tube of the instrument; this, having two opposite surfaces ground flat and polished, and being long enough to include the range of variation, is cemented on to the tube of the instrument with Canada balsam, and would render it easy (by making all but a central slit opake) to get rid of the partial illumination of the column of mercury on the side which is required, for a good impression on the paper, to be quite dark.

The surface of the mercury in the barometer sustains a blackened pith-ball of the same diameter as the bore of the tube, but freely sliding therein; it is proposed however to make a float of platinum foil with a sharp edge, which will probably be found to be more advantageous.

The thermometer used is mercurial, with a broad flat bore.

The wet-bulb, hair hygrometer, \&c., as well as every other instrument which by its action affords a distinct sign, may obviously be registered in the same manner.

Several minor points of difficulty remain still to be overcome, but it is hoped that enough has been done to justify the expectation that the photographic camera may become a really useful and convenient instrument in the hands of the exact meteorologist.

The electrical experiments were made by means of a small conductor, insulated for the occasion; Mr. Ronalds not feeling either authorised, or disposed, to interrupt the course of observations carried on by means of the ordinary high conductor, until the proposed mode of registration is quite matured.

$$
\text { G } 2
$$

